\title{
Patent Foramen Ovale Closure in Old Stroke Patients: A Subgroup Analysis of the DEFENSE-PFO Trial
}

\author{
Hanim Kwon, ${ }^{\mathrm{a}}$ Pil Hyung Lee, ${ }^{\mathrm{b}}$ Jae-Kwan Song, ${ }^{\mathrm{b}}$ Sun U. Kwon, ${ }^{\mathrm{a}}$ Dong-Wha Kang, ${ }^{\mathrm{a}}$ Jong S. Kim ${ }^{\mathrm{a}}$ \\ aDepartment of Neurology, Asan Medical Center, University of Ulsan College of Medicine, Seoul, Korea \\ bDepartment of Cardiology, Asan Medical Center, University of Ulsan College of Medicine, Seoul, Korea
}

\section{Dear Sir:}

Recent randomized trials have shown the benefit of patent foramen ovale (PFO) closure for secondary stroke prevention in patients with high-risk PFO. ${ }^{1-3}$ Because these trials enrolled relatively young ( $<60$ years) patients, the current American Academy of Neurology guidelines recommend PFO closure in stroke patients who are $<60$ years old. ${ }^{4}$ Therefore, the benefit of PFO closure in older patients remains unclear. ${ }^{5}$ Device Closure Versus Medical Therapy for Cryptogenic Stroke Patients With High-Risk Patent Foramen Ovale (DEFENSE-PFO) was a randomized trial that showed that cardio-cerebral vascular events were significantly reduced in the PFO-closure arm than in the medicaltreatment arm. ${ }^{6}$ Since there was no age limit in this study, we aimed to investigate the benefit of PFO closure in older adults. The DEFENSE-PFO trial has been described elsewhere. ${ }^{6}$ Briefly, we enrolled patients who had an ischemic stroke within the previous six months and a high-risk PFO (PFO with an atrial septal aneurysm, hypermobility, or size of $\geq 2 \mathrm{~mm}$ on transesophageal echocardiography) with no other identifiable causes. Patients with significant $(\geq 50 \%)$ cerebral artery steno-occlusion or lacunar infarcts were excluded. The trial was approved by the Institutional Review Board at participating centers, and all patients provided written informed consent.

For this study, patients were grouped into two ( $<60$ and $\geq 60$ years old). The primary endpoint was ischemic stroke or transient ischemic attack (TIA) during 2 years of follow-up. The secondary endpoints included stroke, TIA, vascular death, and Thrombolysis in Myocardial Infarction (TIMI)-defined major bleeding. The baseline characteristics were compared using Pearson's chi-square tests or Fisher's exact test for categorical variables and the Mann-Whitney test for continuous variables, as indicated. All analyses were conducted using the intentionto-treat population. Cumulative incidence was plotted using Kaplan-Meier curves and compared using the log-rank test. The hazard ratio (HR) was evaluated using the penalized maximum likelihood estimation. The interactions between the treatment allocation and age subgroups for each endpoint were evaluated using the Cox proportional hazard model. Considering the small sample of patients with advanced age and the explorative nature of the study, we set the significant $P$-value level as 0.1 rather than 0.05 .

From September 2011 to October 2017, 120 patients (mean age, 52 years; 60 patients in each arm) were enrolled. There were $86(71.7 \%)$ and $34(28.3 \%)$ patients in the $<60$ and $\geq 60$ years groups, respectively. Patients in the $\geq 60$ years group had a higher prevalence of cardiovascular risk factors and lower paradoxical embolism (risk of paradoxical embolism [RoPE]) scores than those in the $<60$ group years (Supplementary Table 1). In the $<60$ and $\geq 60$ years groups, $47(54.7 \%)$ and $13(38.2 \%)$ patients were assigned to the PFO-closure arm, respectively. The baseline characteristics of the patients are summarized in Table 1. The baseline characteristics and anatomic features of PFO were similar in both groups, except for the higher RoPE score (7.6 \pm 1.5 vs. $6.9 \pm 1.2, P=0.02)$ and fewer current smokers $(17.0 \%$ vs. $35.9 \%, P=0.05)$ in the PFO-closure arm of the $<60$ years group.

The median follow-up duration was 2.5 years (interquartile range [IQR], 0.8 to 3.9$)$ for the $<60$ years and PFO closure group, 2.9 years (IQR, 0.9 to 4.6$)$ for the $<60$ years and medical treatment group, 4.4 years (IQR, 3.7 to 5.0 ) for the $\geq 60$ years and PFO closure group, and 2.5 years (IQR, 0.8 to 3.9$)$ for the $\geq 60$ years and medical treatment group. Recurrent ischemic stroke or TIA occurred in six patients; all were from the medical thera- 
Table 1. Baseline characteristics of patients aged $<60$ and $\geq 60$ years

\begin{tabular}{|c|c|c|c|c|c|c|}
\hline \multirow{2}{*}{ Characteristic } & \multicolumn{3}{|c|}{$<60$ Years } & \multicolumn{3}{|c|}{$\geq 60$ Years } \\
\hline & PFO closure $(n=47)$ & Medication only $(n=39)$ & $P$ & PFO closure $(n=13)$ & Medication only $(n=21)$ & $P$ \\
\hline Age (yr) & $44.2 \pm 12.1$ & $47.3 \pm 9.3$ & 0.18 & $67.8 \pm 6.1$ & $67.1 \pm 4.7$ & 0.94 \\
\hline Male sex & $28(59.6)$ & $25(64.1)$ & 0.67 & $5(38.5)$ & $9(42.9)$ & 0.80 \\
\hline \multicolumn{7}{|l|}{ Medical history } \\
\hline Hypertension & $8(17.0)$ & $7(17.9)$ & 0.91 & $4(30.8)$ & $10(47.6)$ & 0.33 \\
\hline Diabetes & $2(4.3)$ & $4(10.3)$ & 0.40 & $4(30.8)$ & $4(19.0)$ & 0.68 \\
\hline Current smoker & $8(17.0)$ & $14(35.9)$ & 0.05 & $2(15.4)$ & $2(9.5)$ & 0.63 \\
\hline Hypercholesterolemia & $12(25.5)$ & $14(35.9)$ & 0.30 & $6(46.2)$ & $11(52.4)$ & $>0.99$ \\
\hline Modified Rankin Scale & & & 0.30 & & & 0.29 \\
\hline $0-1$ & $38(80.9)$ & $30(76.9)$ & & $10(76.9)$ & $12(57.1)$ & \\
\hline $2-3$ & $9(19.1)$ & $9(23.1)$ & & $3(23.1)$ & $9(42.9)$ & \\
\hline RoPE score & $7.6 \pm 1.5$ & $6.9 \pm 1.2$ & 0.02 & $4.5 \pm 1.0$ & $4.6 \pm 1.2$ & 0.51 \\
\hline Shunt at rest & & & 0.38 & & & 0.53 \\
\hline No shunt & 18 (39.1) & $17(43.6)$ & & $7(53.8)$ & $9(42.9)$ & \\
\hline Left-to-right shunt & $25(54.3)$ & $22(56.4)$ & & $6(46.2)$ & $12(57.1)$ & \\
\hline Right-to-left shunt & $3(6.5)$ & $0(0)$ & & $0(0)$ & $0(0)$ & \\
\hline Bidirectional shunt & $1(2.1)$ & $0(0)$ & & $0(0)$ & $0(0)$ & \\
\hline PFO size $(\mathrm{mm})$ & $3.3 \pm 1.6$ & $3.2 \pm 1.0$ & 0.53 & $2.7 \pm 1.0$ & $3.1 \pm 1.2$ & 0.19 \\
\hline TEE $>20$ microbubbles & $38(56.7)$ & $29(43.3)$ & 0.47 & $12(92.3)$ & $17(81.0)$ & 0.63 \\
\hline Atrial septal aneurysm & $3(6.4)$ & $5(12.8)$ & 0.46 & $2(15.4)$ & $3(14.3)$ & $>0.99$ \\
\hline Atrial septal hypermobility & $22(46.8)$ & $17(43.6)$ & 0.77 & $6(46.2)$ & $10(47.6)$ & 0.93 \\
\hline
\end{tabular}

Values are presented as mean \pm standard deviation or number (\%).

PFO, patent foramen ovale; RoPE, risk of paradoxical embolism; TEE, transesophageal echocardiography.

Table 2. Outcomes of patients aged aged $<60$ and $\geq 60$ years

\begin{tabular}{|c|c|c|c|c|c|c|}
\hline \multirow{2}{*}{ Variable } & \multicolumn{3}{|c|}{$<60$ Years } & \multicolumn{3}{|c|}{$\geq 60$ Years } \\
\hline & PFO closure $(n=47)$ & Medication only $(n=39)$ & $P$ & PFO closure $(n=13)$ & Medication only $(n=21)$ & $P$ \\
\hline \multicolumn{7}{|l|}{ Primary endpoint } \\
\hline $\begin{array}{l}\text { Ischemic stroke or transient } \\
\text { ischemic attack }\end{array}$ & $0(0)$ & $2(5.1)$ & 0.12 & $0(0)$ & $4(19.0)$ & 0.07 \\
\hline 2-Year event rate (\%) & NA & 5.8 & & NA & 24.6 & \\
\hline Hazard ratio $(95 \% \mathrm{Cl})$ & \multicolumn{2}{|c|}{5.99 (0.15-246.68) } & 0.35 & \multicolumn{2}{|c|}{$7.36(0.28-195.81)$} & 0.23 \\
\hline \multicolumn{7}{|l|}{ Secondary endpoint } \\
\hline Ischemic stroke & $0(0)$ & $2(5.1)$ & 0.12 & $0(0)$ & $3(14.3)$ & 0.12 \\
\hline Vascular death & $0(0)$ & $0(0)$ & NA & $0(0)$ & $0(0)$ & NA \\
\hline TIMI-defined major bleeding & $0(0)$ & $1(2.6)$ & 0.28 & $0(0)$ & $1(4.8)$ & 0.41 \\
\hline Hemorrhagic stroke & $0(0)$ & $1(2.6)$ & 0.28 & $0(0)$ & $0(0)$ & NA \\
\hline Transient ischemic attack & $0(0)$ & $0(0)$ & NA & $0(0)$ & $1(4.8)$ & 0.41 \\
\hline Systemic embolization & $0(0)$ & $0(0)$ & NA & $0(0)$ & $0(0)$ & NA \\
\hline
\end{tabular}

Values are presented as number (\%).

PFO, patent foramen ovale; NA, not applicable; $\mathrm{Cl}$, confidence interval; TIMI, Thrombolysis in Myocardial Infarction.

py arm (Table 2). The Kaplan-Meier curve showed no difference (2-year event rate, 5.8\%; HR, 5.99; 95\% confidence interval [Cl], 0.15 to 246.68 ; log-rank $P=0.12$ ) in the $<60$ years group; it showed a difference (2-year event rate, 24.6\%; HR, 7.36; 95\% $\mathrm{Cl}, 0.28$ to 195.81 ; log-rank $P=0.07$ ) between the two treatment arms in the $\geq 60$ years group (Figure 1 ). $P$-value for interaction 


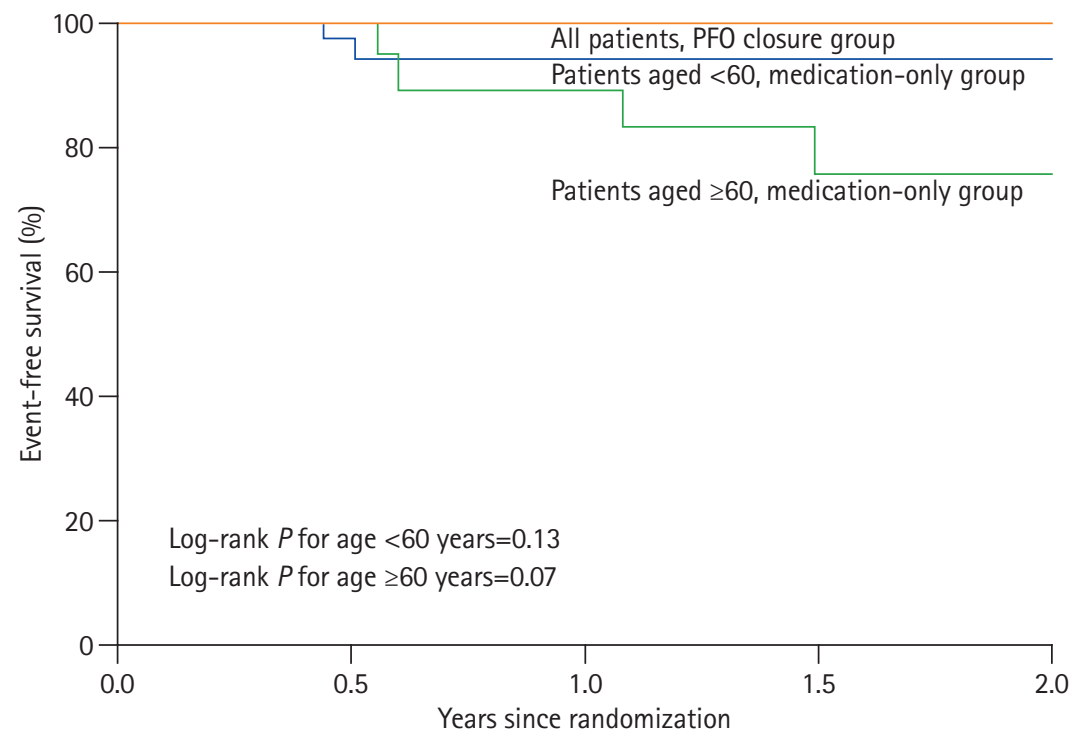

Number at risk

Age $<60$ years

$\begin{array}{llllll}\text { PFO closure } & 47 & 39 & 35 & 31 & 29\end{array}$

$\begin{array}{llllll}\text { Medication-only } & 39 & 32 & 28 & 26\end{array}$

Age $\geq 60$ years

PFO closure $\quad 13$

Medication-only 21

$13 \quad 12$

$12 \quad 12$

$\begin{array}{llll}19 & 15 & 10 & 10\end{array}$

Figure 1. Kaplan-Meier estimates for patent foramen ovale (PFO) closure and primary endpoint. Event-free survival of all the patients in the PFO-closure group (red line), patients aged $<60$ years in the medical-treatment group (blue line), and patients aged $\geq 60$ years in the medical-treatment group (green line).

was 0.96 . When the ages of the patients were $\geq 70$ years, the incidence of the primary outcome was significantly higher in the medication group than in the PFO closure group (2-year event rate, $80 \%$; $\mathrm{HR}, 11.64 ; 95 \% \mathrm{Cl}, 0.43$ to 318.81 ; log-rank $P=0.03$ ) (Supplementary Table 2 and Supplementary Figure 1). The magnetic resonance imaging (MRI) findings for five patients with recurrent ischemic stroke are summarized in Supplementary Table 3. All recurrent strokes were regarded as embolic infarctions because there was no significant cerebral artery stenosis. Electrocardiography and Holter examinations were performed for all the patients at the time of the initial stroke and repeated for four and two patients, respectively, at the time of recurrence. No embolic causes (e.g., atrial fibrillation) were identified. None of the patients showed MRI findings of lacunar infarction (subcortical infarcts with diameter $<20 \mathrm{~mm}$ ) during the initial and recurrent strokes.

The main DEFENSE-PFO trial showed that PFO closure was effective in preventing recurrent ischemic stroke and some major vascular events. ${ }^{6}$ This sub-study indicates that the benefit is greater in patients aged $\geq 60$ years than in younger patients. Further analysis showed that PFO closure was even more effective in patients aged $\geq 70$ years. The interaction analysis, however, did not show significant differences in the primary outcomes across the age groups. Nevertheless, the tendency of a better clinical response to PFO closure in old patients may be attributed to their higher frequency of recurrent strokes regardless of treatment (Supplementary Figure 2). Although PFO size may increase with age, ${ }^{7}$ there were no significant differences in the PFO size and the prevalence of atrial septal aneurysm and hypermobility in the groups, probably because only patients with high-risk PFO were enrolled in our trial. Thus, morphological PFO characteristics cannot adequately explain our observations. Although vascular risk factors increased with age, all cases of recurrent stroke were regarded as embolic. Previous studies demonstrated that recurrent stroke is common in old patients with $\mathrm{PFO}_{1}^{89}$ possibly due to the increased prevalence of venous thrombosis ${ }^{10}$ or increased right ventricular pressure that promotes right-to-left shunting. ${ }^{11}$ Our findings, therefore, suggest that PFO closure may be needed in older adult patients who are prone to recurrent strokes.

This study has limitations. (1) This subgroup analysis was not prespecified but post hoc. (2) The number of older patients was small; therefore, the results were not adequately powered and may have been a consequence of chance. (3) Although a Holter examination was performed for all patients for the initial stroke, not all patients with recurrent stroke underwent repeated exam- 
inations. Despite these limitations, our data suggest that PFO closure may be effective in preventing recurrent stroke in older patients. Although randomized trials involving more patients are required to confirm our preliminary findings, we suggest that PFO closure should be considered seriously, even in older patients.

\section{Supplementary materials}

Supplementary materials related to this article can be found online at https://doi.org/10.5853/jos.2021.00647.

\section{References}

1. Saver JL, Carroll JD, Thaler DE, Smalling RW, MacDonald LA, Marks DS, et al. Long-term outcomes of patent foramen ovale closure or medical therapy after stroke. N Engl J Med 2017; 377:1022-1032.

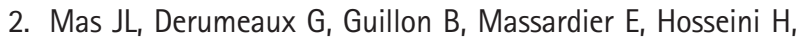
Mechtouff $L$, et al. Patent foramen ovale closure or anticoagulation vs. antiplatelets after stroke. N Engl J Med 2017;377: 1011-1021.

3. Søndergaard L, Kasner SE, Rhodes JF, Andersen G, Iversen HK, Nielsen-Kudsk JE, et al. Patent foramen ovale closure or antiplatelet therapy for cryptogenic stroke. N Engl J Med 2017; 377:1033-1042.

4. Messé SR, Gronseth GS, Kent DM, Kizer JR, Homma S, Rosterman $L$, et al. Practice advisory update summary: patent foramen ovale and secondary stroke prevention: report of the Guideline Subcommittee of the American Academy of Neurology. Neurology 2020;94:876-885.

5. Köhrmann M, Schellinger PD, Tsivgoulis G, Steiner T. Patent foramen ovale: story closed? J Stroke 2019;21:23-30.

6. Lee PH, Song JK, Kim JS, Heo R, Lee S, Kim DH, et al. Cryptogenic stroke and high-risk patent foramen ovale: the DE-
FENSE-PFO trial. J Am Coll Cardiol 2018;71:2335-2342.

7. Hagen PT, Scholz DG, Edwards WD. Incidence and size of patent foramen ovale during the first 10 decades of life: an autopsy study of 965 normal hearts. Mayo Clin Proc 1984;59: 17-20.

8. Homma S, DiTullio MR, Sacco RL, Sciacca RR, Mohr JP; PICSS Investigators. Age as a determinant of adverse events in medically treated cryptogenic stroke patients with patent foramen ovale. Stroke 2004;35:2145-2149.

9. Mazzucco S, Li L, Rothwell PM. Prognosis of cryptogenic stroke with patent foramen ovale at older ages and implications for trials: a population-based study and systematic review. JAMA Neurol 2020;77:1279-1287.

10. Gregson J, Kaptoge S, Bolton T, Pennells L, Willeit P, Burgess S, et al. Cardiovascular risk factors associated with venous thromboembolism. JAMA Cardiol 2019;4:163-173.

11. McQuillan BM, Picard MH, Leavitt M, Weyman AE. Clinical correlates and reference intervals for pulmonary artery systolic pressure among echocardiographically normal subjects. Circulation 2001;104:2797-2802.

Correspondence: Jong S. Kim

Department of Neurology, Asan Medical Center, University of Ulsan College of Medicine, 88 Olympic-ro 43-gil, Songpa-gu, Seoul 05505, Korea

Tel: $+82-2-3010-3442$

Fax: +82-2-474-4691

E-mail: jongskim@amc.seoul.kr

https://orcid.org/0000-0002-3999-4992

Received: February 17, 2021

Revised: April 27, 2021

Accepted: April 28, 2021

This work was supported by a research grant from the Cardiovascular Research Foundation, Seoul, South Korea.

The authors have no financial conflicts of interest. 
Supplementary Table 1. Baseline characteristics of the patients according to age

\begin{tabular}{|c|c|c|c|}
\hline Characteristic & Age $<60$ years $(n=86)$ & Age $\geq 60$ years $(n=34)$ & $P$ \\
\hline Age (yr) & $45.6 \pm 10.9$ & $67.3 \pm 5.2$ & $<0.001$ \\
\hline Male sex & $52(61.6)$ & $14(41.2)$ & 0.04 \\
\hline \multicolumn{4}{|l|}{ Medical history } \\
\hline Hypertension & $15(17.4)$ & $14(41.2)$ & 0.01 \\
\hline Diabetes & $1(7.0)$ & $8(23.5)$ & 0.02 \\
\hline Current smoker & $22(25.6)$ & $4(11.8)$ & 0.10 \\
\hline Hypercholesterolemia & $26(30.2)$ & $17(50.0)$ & 0.04 \\
\hline Qualifying event & & & 0.09 \\
\hline Anterior circulatory territory & $40(46.5)$ & $22(64.7)$ & \\
\hline Multiple territories & $1(1.2)$ & $1(2.9)$ & \\
\hline Modified Rankin Scale & & & 0.10 \\
\hline $0-1$ & $68(79.1)$ & $22(64.7)$ & \\
\hline $2-3$ & $18(20.9)$ & $12(35.3)$ & \\
\hline RoPE score & $7.3 \pm 1.4$ & $4.56 \pm 1.1$ & $<0.001$ \\
\hline Shunt at rest & & & 0.62 \\
\hline No shunt & $16(47.1)$ & $35(41.2)$ & \\
\hline Left-to-right shunt & $18(52.9)$ & $47(55.3)$ & \\
\hline Right-to-left shunt & $0(0)$ & $3(3.5)$ & \\
\hline Bidirectional shunt & $0(0)$ & $0(0)$ & \\
\hline TEE >20 microbubbles & $67(77.9)$ & 29 (85.3) & 0.36 \\
\hline PFO size $(\mathrm{mm})$ & $3.3 \pm 1.4$ & $2.9 \pm 1.1$ & 0.13 \\
\hline Atrial septal aneurysm & $8(9.3)$ & $5(14.7)$ & 0.52 \\
\hline Atrial septal hypermobility & $39(45.3)$ & $16(47.1)$ & 0.87 \\
\hline
\end{tabular}

Values are presented as mean \pm standard deviation or number (\%).

RoPE, risk of paradoxical embolism; TEE, transesophageal echocardiography; PFO, patent foramen ovale. 
Supplementary Table 2. Outcomes of patients according to age

\begin{tabular}{|c|c|c|c|c|c|c|}
\hline \multirow{2}{*}{ Variable } & \multicolumn{3}{|c|}{$<70$ Years } & \multicolumn{3}{|c|}{$\geq 70$ Years } \\
\hline & PFO closure $(n=55)$ & Medication only $(n=54)$ & $P$ & PFO closure $(n=5)$ & Medication only ( $n=6$ ) & $P$ \\
\hline Follow-up period (yr) & $2.9(1.1-4.3)$ & $2.9(0.9-4.6)$ & & $3.8(2.1-4.5)$ & $0.8(0.5-2.1)$ & \\
\hline \multicolumn{7}{|l|}{ Primary endpoint } \\
\hline Ischemic stroke or transient ischemic attack & $0(0)$ & $2(3.7)$ & 0.16 & $0(0)$ & $4(66.7)$ & 0.03 \\
\hline \multicolumn{7}{|l|}{ Secondary endpoint } \\
\hline Ischemic stroke & $0(0)$ & $2(3.7)$ & 0.16 & $0(0)$ & $3(50.0)$ & 0.12 \\
\hline Vascular death & $0(0)$ & $0(0)$ & NA & $0(0)$ & $0(0)$ & NA \\
\hline TIMI-defined major bleeding & $0(0)$ & $1(1.9)$ & 0.29 & $0(0)$ & $1(16.7)$ & 0.32 \\
\hline Hemorrhagic stroke & $0(0)$ & $1(1.9)$ & 0.29 & $0(0)$ & $0(0)$ & NA \\
\hline Transient ischemic attack & $0(0)$ & $0(0)$ & NA & $0(0)$ & $1(16.7)$ & 0.32 \\
\hline Systemic embolization & $0(0)$ & $0(0)$ & NA & $0(0)$ & $0(0)$ & NA \\
\hline
\end{tabular}

Values are presented as median (interquartile range) or number (\%).

PFO, patent foramen ovale; NA, not applicable; TIMI, Thrombolysis in Myocardial Infarction.

Supplementary Table 3. Magnetic resonance imaging characteristics of stroke in patients with recurrence stroke

\begin{tabular}{cccccccccc}
\hline \multirow{2}{*}{ No. } & Age (yr) & PFO closure & \multicolumn{2}{c}{ Location } & $\begin{array}{c}\text { Multiple lesions } \\
\text { (initial/recur) }\end{array}$ & $\begin{array}{c}\text { Cortical lesion } \\
\text { (initial/recur) }\end{array}$ & $\begin{array}{c}\text { Hemorragic change } \\
\text { (initial/recur) }\end{array}$ & $\begin{array}{c}\text { Ipsilateral artery } \\
\text { stenosis (initial/recur) }\end{array}$ & $\begin{array}{c}\text { Mechanism at } \\
\text { recur }\end{array}$ \\
\hline 1 & 73 & - & Lt. Ant. & Lt. Ant. & $-/-$ & $+/-$ & $-/-$ & $-/-$ & Embolic \\
2 & 72 & - & Lt. Ant. Post. Both Ant. & $+/+$ & $+/+$ & $-/-$ & $-/-$ & Embolic \\
3 & 51 & - & Rt. Ant. & Rt. Ant. & $-/-$ & $+/-$ & $-/-$ & $-/-$ & Embolic \\
4 & 75 & - & Rt. Ant. & Lt. Ant. & $+/-$ & $+/+$ & $-/+$ & $-/-$ & Embolic \\
5 & 50 & - & Lt. Ant. & Rt. Ant. & $+/+$ & $+/+$ & $-/-$ & $-/-$ & Embolic \\
\hline
\end{tabular}

PFO, patent foramen ovale; Lt., left; Ant., anterior; -, absent; +, present; Post., posterior; Rt., right. 


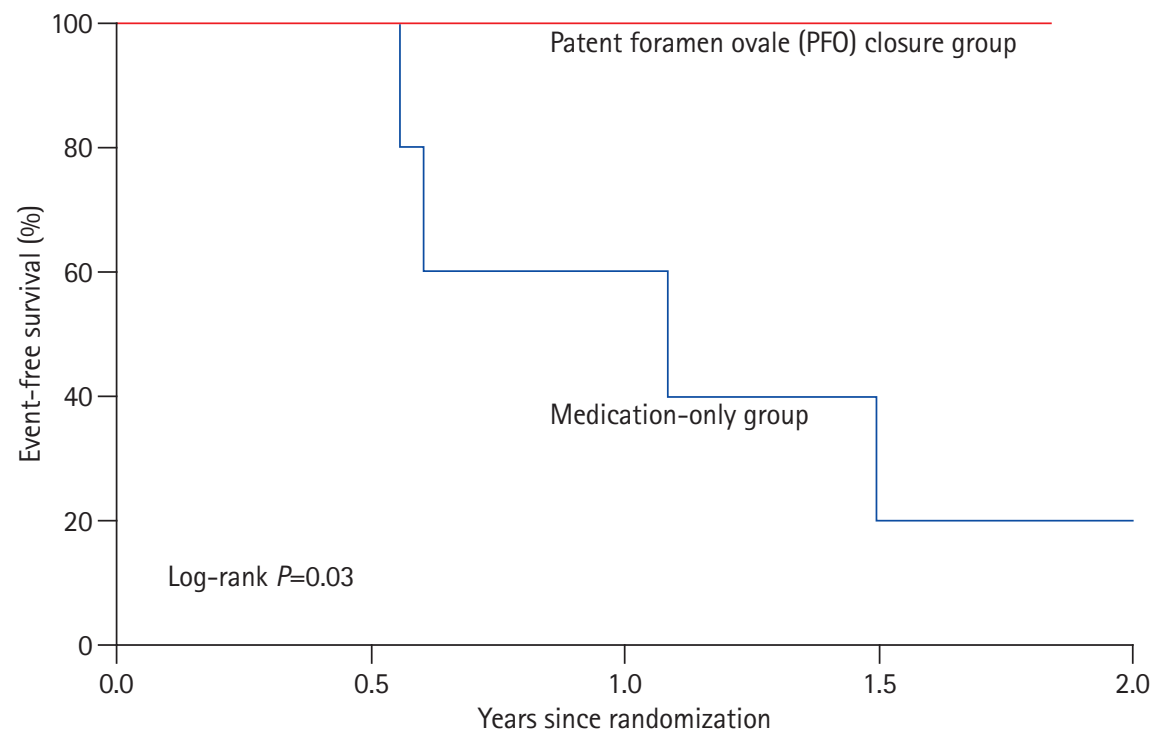

Number at risk

$\begin{array}{llllll}\text { PFO closure } & 5 & 5 & 4 & 4 & 4 \\ \text { Medication-only } & 6 & 5 & 3 & 1 & 1\end{array}$

Supplementary Figure 1. Kaplan-Meier estimate for primary endpoint in age $\geq 70$ years group. Event-free survival of the primary endpoint in the patent foramen ovale (PFO)-closure group (red line) versus the medical-treatment group (blue line) (log rank $P=0.03$ ).

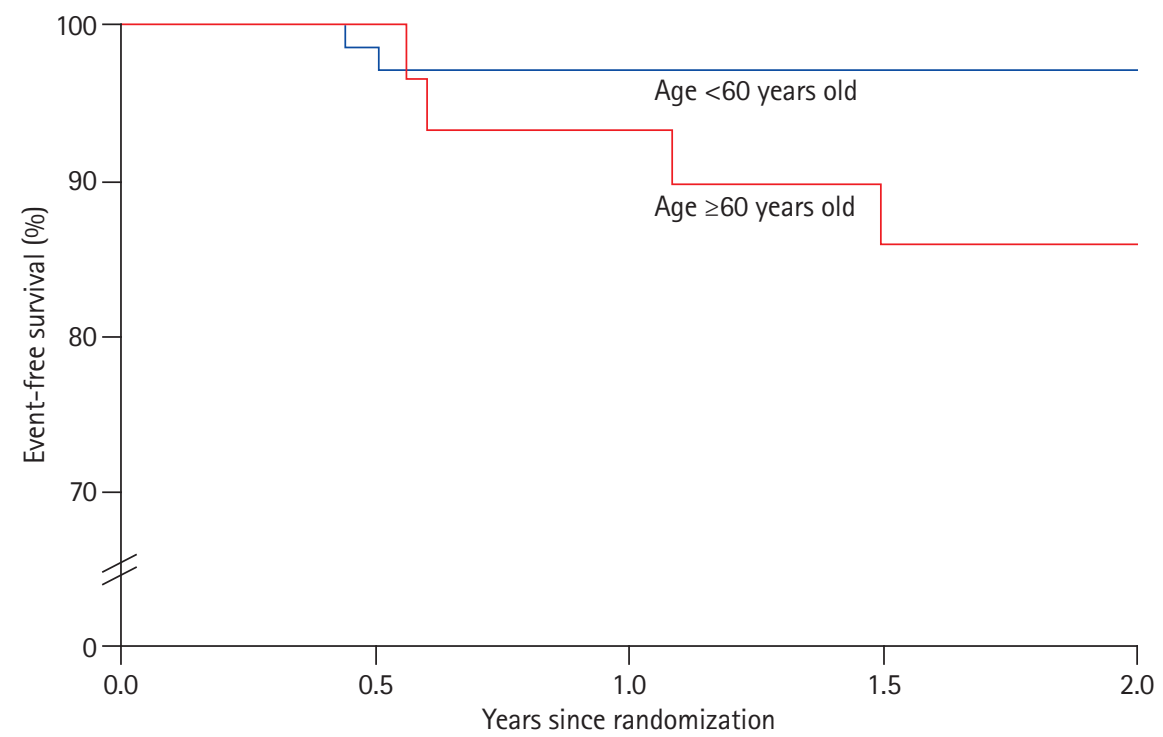

Number at risk

$\begin{array}{llllll}\text { Age }<60 \text { years old } & 86 & 71 & 63 & 57 & 54 \\ \text { Age } \geq 60 \text { years old } & 34 & 32 & 27 & 22 & 22\end{array}$

Supplementary Figure 2. Kaplan-Meier estimate for primary endpoint according to age. Graph showing primary endpoint event free survival in $<60$ years group versus $\geq 60$ years group. 